\title{
Comunicação
}

[Communication]

\section{Parâmetros hematológicos de jumentas gestantes em diferentes períodos}

\author{
[Hematological parameters of pregnant donkeys in different periods]

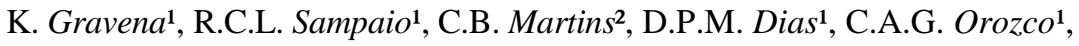 \\ J.V. Oliveira ${ }^{3}$, J.C. Lacerda-Neto ${ }^{1 *}$ \\ ${ }^{1}$ Faculdade de Ciências Agrárias e Veterinárias - UNESP \\ Via de Acesso Prof. Paulo Donato Castellane, s/n \\ 14870-000 - Jaboticabal, SP \\ ${ }^{2}$ Centro de Ciências Agrárias - UFES - Alegre, ES
}

${ }^{3}$ Haras Polo Regional de Desenvolvimento Tecnológico de Agronegócios da Alta Mogiana - Colina, SP

\begin{abstract}
A criação de equídeos no Brasil tem evoluído consideravelmente nos últimos anos. Durante o período de gestação, nos equídeos ocorrem mudanças fisiológicas que geram maior demanda corporal para sua própria manutenção e do concepto, aumentando as exigências nutricionais e ocasionando alterações de suas constantes fisiológicas, inclusive hematológicas. Portanto, o conhecimento dessas modificações pode ser de grande utilidade no acompanhamento e manejo dessas fêmeas.
\end{abstract}

São poucos os estudos realizados em condições tropicais com jumentos. O trabalho realizado por Perdigão de Oliveira et al. (1974) encontrou as seguintes variações no hemograma: hemácias (He) $6,62 \pm 1,02 \times 10^{6} / \mu \mathrm{L}$; hemoglobina (Hb) $12,24 \pm 1,54 \mathrm{~g} / \mathrm{dL}$; volume globular (VG) $33,82 \pm 4.57 \%$; volume globular médio (VGM) 52,82 \pm ,48fL; hemoglobina globular média

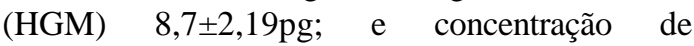
hemoglobina globular média (CHGM) $35,85 \pm 2,43 \mathrm{~g} / \mathrm{dL}$.

Mori et al. (2004) estabeleceram os seguintes valores hematológicos de referência para jumentos saudáveis da raça Brasileiro: $6,82 \pm 0,67 \times 10^{6} \mathrm{He} / \mu \mathrm{L} ; 12,87 \pm 0,98 \mathrm{~g}$ de $\mathrm{Hb} / \mathrm{dL}$; VG de $37,63 \pm 2,76 \%$; VGM de 55,45 $\pm 4,06 f L$; HGM de 18,85 $\pm 1,14 p g ;$ CHCM de

Recebido em 6 de maio de 2010

Aceito em 29 de novembro de 2010

*Autor para correspondência (corresponding author)

E-mail: jlacerda@fcav.unesp.br
34,20 $\pm 1,24 \mathrm{~g} / \mathrm{dL} ; \quad 8,22 \pm 1,49 \times 10^{3}$ leucócitos/ $\mu \mathrm{L}$; $3,39 \pm 0,81 \times 10^{3}$ neutrófilos segmentados $/ \mu \mathrm{L}$; $4,15 \pm 0,84 \times 10^{3} \quad$ linfócitos $/ \mu \mathrm{L} ; \quad 0,13 \pm 0,11 \times 10^{3}$ monócitos $/ \mu \mathrm{L} ; 0,03 \pm 0,04 \times 10^{3}$ basófilos $/ \mu \mathrm{L}$.

O presente estudo teve como objetivo avaliar os parâmetros eritrométricos, leucométricos e a concentração plasmática de proteína total de jumentas sadias, da raça Marchador Brasileiro, sob condições de pasto, em clima tropical.

Foram utilizadas 52 jumentas sadias, entre oito e 16 anos de idade, das quais 36 estavam prenhes, e 16 não prenhes. Os grupos de coletas foram distribuídos em jumentas não prenhes (controle), prenhes entre 25 a 110 dias (primeira fase), entre 111 a 210 dias (segunda fase) e entre 211 a 340 dias (terceira fase) de gestação. Após a coleta de sangue, as amostras foram mantidas a $4^{\circ} \mathrm{C}$ até a análise. Realizaram-se as contagens globais de $\mathrm{He}$, concentração de $\mathrm{Hb}$, determinação do VG, e calcularam-se os índices hematimétricos, VGM, HGM e CHGM. Também foram realizadas contagens global e diferencial de leucócitos (Le) e a concentração plasmática de proteína total (PT). Os valores obtidos foram submetidos à análise estatística pelo programa computacional SAS, utilizando-se análise de variância. As comparações entre médias foram feitas pelo teste Tukey. 
Observou-se aumento no número de He e nas concentrações de Hb e CHGM na terceira fase de gestação (211 - 340 dias), a qual diferiu das outras fases e do grupo-controle (Tab. 1). Porém, houve diminuição no VGM e no HGM nessa mesma fase, que diferiu de todas as outras fases e do controle.
Já o teor plasmático de PT apresentou queda significativa na primeira fase da gestação.

No leucograma, pode ser observada diminuição no número de eosinófilos na primeira fase da gestação, a qual difere dos resultados do grupocontrole e da segunda fase gestacional (Tab. 2).

Tabela 1. Valores médios e erro-padrão do eritrograma e da concentração plasmática de proteína total de jumentas da raça Marchador Brasileiro durante a gestação

\begin{tabular}{lcccc} 
Variável & $\begin{array}{c}\text { Éguas vazias } \\
(\text { Controle })\end{array}$ & $\begin{array}{c}\text { Éguas gestantes } \\
(25 \text { a } 110 \text { dias }) \\
(\mathrm{n}=14)\end{array}$ & $\begin{array}{c}\text { Éguas gestantes } \\
(111 \text { a } 210 \text { dias }) \\
(\mathrm{n}=12)\end{array}$ & $\begin{array}{c}\text { Éguas gestantes } \\
(211 \text { a } 340 \text { dias }) \\
(\mathrm{n}=10)\end{array}$ \\
\hline He $\left(\times 10^{6} / \mu \mathrm{L}\right)$ & $5,40 \pm 0,12 \mathrm{~b}$ & $5,50 \pm 0,15 \mathrm{~b}$ & $5,34 \pm 0,10 \mathrm{~b}$ & $7,05 \pm 0,12 \mathrm{a}$ \\
VG $(\%)$ & $35,19 \pm 0,77 \mathrm{a}$ & $35,00 \pm 0,91 \mathrm{a}$ & $35,42 \pm 0,83 \mathrm{a}$ & $36,90 \pm 0,84 \mathrm{a}$ \\
$\mathrm{Hb}(\mathrm{g} / \mathrm{dL})$ & $12,12 \pm 0,19 \mathrm{~b}$ & $11,45 \pm 0,31 \mathrm{~b}$ & $11,84 \pm 0,28 \mathrm{~b}$ & $13,36 \pm 0,37 \mathrm{a}$ \\
VGM (fL) & $65,18 \pm 0,65 \mathrm{a}$ & $63,67 \pm 0,95 \mathrm{a}$ & $66,47 \pm 1,74 \mathrm{a}$ & $52,38 \pm 0,75 \mathrm{~b}$ \\
HGM (pg) & $22,50 \pm 0,28 \mathrm{a}$ & $20,85 \pm 0,43 \mathrm{~b}$ & $22,22 \pm 0,55 \mathrm{ab}$ & $18,94 \pm 0,47 \mathrm{c}$ \\
CHGM (g/dL) & $34,52 \pm 0,28 \mathrm{~b}$ & $32,72 \pm 0,36 \mathrm{c}$ & $33,45 \pm 0,24 \mathrm{bc}$ & $36,21 \pm 0,62 \mathrm{a}$ \\
PT (g/dL) & $7,69 \pm 0,11 \mathrm{a}$ & $6,91 \pm 0,07 \mathrm{~b}$ & $7,58 \pm 0,10 \mathrm{a}$ & $7,64 \pm 0,15 \mathrm{a}$ \\
\hline
\end{tabular}

HE: hemácias; VG: volume globular; Hb: teor de hemoglobina; VGM: volume globular médio; HGM: hemoglobina globular média; CHGM: concentração de hemoglobina globular média, PT: proteína total.

Letras diferentes indicam médias com diferença estatística significativa $(\mathrm{P}<0,05)$.

Tabela 2. Valores médios e erro-padrão obtidos no leucograma de jumentas da raça Marchador Brasileiro durante a gestação

\begin{tabular}{lcccc}
$\begin{array}{l}\text { Variável } \\
\left(\mathrm{x} 10^{3} \mu \mathrm{L}\right)\end{array}$ & $\begin{array}{c}\text { Éguas vazias } \\
(\text { Controle }) \\
(\mathrm{n}=16)\end{array}$ & $\begin{array}{c}\text { Éguas gestantes } \\
(25 \mathrm{a} 110 \text { dias }) \\
(\mathrm{n}=14)\end{array}$ & $\begin{array}{c}\text { Éguas gestantes } \\
(111 \mathrm{a} 210 \text { dias }) \\
(\mathrm{n}=12)\end{array}$ & $\begin{array}{c}\text { Éguas gestantes } \\
(211 \text { a } 340 \text { dias }) \\
(\mathrm{n}=10)\end{array}$ \\
\hline Leucócitos & $7,05 \pm 0,23 \mathrm{a}$ & $6,85 \pm 0,49 \mathrm{a}$ & $7,43 \pm 0,28 \mathrm{a}$ & $7,52 \pm 0,46 \mathrm{a}$ \\
$\mathrm{NS}$ & $2,914 \pm 0,230 \mathrm{a}$ & $2,794 \pm 0,304 \mathrm{a}$ & $2,790 \pm 0,380 \mathrm{a}$ & $3,532 \pm 0,431 \mathrm{a}$ \\
$\mathrm{NB}$ & $0,012 \pm 0,006 \mathrm{a}$ & $0,017 \pm 0,009 \mathrm{a}$ & $0,019 \pm 0,013 \mathrm{a}$ & $0,017 \pm 0,011 \mathrm{a}$ \\
Linfócitos & $3,060 \pm 0,175 \mathrm{a}$ & $3,400 \pm 0,302 \mathrm{a}$ & $3,468 \pm 0,200 \mathrm{a}$ & $3,303 \pm 0,144 \mathrm{a}$ \\
Eosinófilos & $0,927 \pm 0,100 \mathrm{a}$ & $0,450 \pm 0,084 \mathrm{~b}$ & $0,946 \pm 0,189 \mathrm{a}$ & $0,517 \pm 0,098 \mathrm{ab}$ \\
Basófilos & $0,003 \pm 0,003 \mathrm{a}$ & $0,036 \pm 0,012 \mathrm{a}$ & $0,020 \pm 0,011 \mathrm{a}$ & $0,019 \pm 0,012 \mathrm{a}$ \\
Monócitos & $0,149 \pm 0,020 \mathrm{a}$ & $0,150 \pm 0,038 \mathrm{a}$ & $0,135 \pm 0,017 \mathrm{a}$ & $0,129 \pm 0,015 \mathrm{a}$ \\
\hline
\end{tabular}

NS: neutrófilos segmentados; NB: neutrófilos bastonetes.

Letras diferentes nas linhas indicam médias com diferença significativa $(\mathrm{P}<0,05)$.

No segundo período de gestação, é maior o crescimento fetal, com subsequente aumento da taxa metabólica e maior demanda de oxigênio, o que estimula a liberação de eritropoetina pelo tecido renal, com consequente aumento no número de hemácias circulantes (Souza et al., 2002). Entretanto, neste estudo, o aumento no número de He foi identificado apenas na fase final da gestação, o qual não ultrapassou os valores de referência estabelecidos para jumentos (Mori et al., 2004). Os valores de VGM e HGM diminuíram na fase final da gestação, ao contrário do observado por Lurie (1993), em mulheres grávidas, e aos valores encontrados por Morris (1998), que atribuiu o aumento à possível presença de eritrócitos imaturos no sangue periférico. Os resultados obtidos neste estudo para VGM e HGM podem estar relacionados ao aumento de $\mathrm{Hb}$ ocorrido no terço final da gestação. Infere-se, pelos resultados deste trabalho, que, em jumentos, ocorre no terço final aumento da taxa metabólica, necessária para suprir o rápido crescimento fetal e a preparação para o parto. Concomitantemente ao aumento do metabolismo, há maior demanda de oxigênio, que estimula uma resposta adaptativa na qual ocorre 
aumento da concentração de $\mathrm{Hb}$, elevando, dessa forma, a quantidade de oxigênio transportado. $\mathrm{O}$ valor de CHGM foi maior na última fase de gestação, porém estes parâmetros não apresentaram nenhuma relevância clínica e estão dentro dos valores de referência para jumentos (Mori et al., 2004).

Relativamente ao leucograma, os valores obtidos para leucócitos não diferiram entre as fases. Os valores de eosinófilos foram elevados no grupocontrole e na segunda fase gestacional. Considerando-se que os eosinófilos refletem uma resposta imunomediada do organismo a processos parasitários e alérgicos, é lícito inferir que, neste caso, o maior número de eosinófilos indicaria maior resistência para suportar cargas parasitárias às quais estes animais, especialmente por estarem em pasto, estão sujeitos no final da gestação (Kaneko et al., 1997).
A diminuição obtida para a concentração plasmática de PT na primeira fase gestacional não apresentou relevância clínica e está dentro dos intervalos de referência estabelecidos para jumentos (Mori et al., 2004). Morris (1993) destacou que inúmeros fatores podem influenciar na concentração plasmática de PT, como a demanda metabólica, o equilíbrio hormonal, o estado nutricional, o equilíbrio ácido-base, entre outros.

Os resultados obtidos neste trabalho indicam parâmetros normais para jumentas da raça Marchador Brasileiro. Estes dados podem ser utilizados pelos médicos veterinários na avaliação da higidez de jumentas tanto desta raça como de outras, durante exames pré-natais.

Palavras-chaves: jumenta, gestação, hemograma, leucograma

\begin{abstract}
The hematological parameters and total protein concentration in healthy donkeys during pregnancy, under grass handling conditions in tropical weather, were evaluated. Fifth-two Marchador Brasileiro breed healthy donkeys, ranging from 8 to 16 years old, were evaluated, 36 of which were pregnant. The animals were separated in four groups: non pregnant (control), pregnancy from 25 to 110 days (first phase), from 111 to 210 days (second phase), and from 211 to 340 days (third phase). Total protein, erythrocyte, and leukocytes counts; packed cell volume; hemoglobin concentration; hematimetric absolute rates of mean corpuscular volume (MCV); mean corpuscular hemoglobin (MCH); and mean corpuscular hemoglobin concentration (MCHC) were evaluated. Total protein and eosinophils count decreased in the first phase. Red blood cells, hemoglobin concentration, and MCHC increased in the third phase of pregnancy. However, MCV and MCH decreased in the same phase.
\end{abstract}

Keywords: donkey, pregnancy, hemogram, leukogram

\section{REFERÊNCIAS BIBLIOGRÁFICAS}

KANEKO, J.J.; HARVEY, J.W.; BRUSS, M.L. (Eds). Clinical biochemistry of domestic animals. 5.ed. San Diego: Academic, 1997.

LURIE, S. Changes in age distribution of erythrocytes during pregnancy: a longitudinal study. Gynecol. Obst. Invest., v.36, p.141-144, 1993.

MORI, E.; MIRANDOLA, R.M.S.; FERREIRA, R.R. et al. Reference values on hematologic parameters of the Brazilian Donkey (Equus asinus) breed. J. Equine Vet. Sci., v.24, p.271-276, 2004.
MORRIS, D.D. Enfermedades del sistema hemolinfático, In: COLAHAN, P.T.; MAYHEW, I.G.; MERRITT, A.M. et al. (Eds). Medicina y Cirugia Equina. Buenos Aires: Inter-Médica. p.1619-1678, 1998.

PERDIGÃO DE OLIVEIRA, F.R.A.; AUGUSTO, C.; GRASSO, P.L. et al. Eritrograma normal de jumentos Equus Asinus das raças puro-sangue Italiana e Brasileira de 1 a 2 anos de idade. Bol. Industr. Anim., v.31, p.325329, 1974.

SOUZA, A.I.; FILHO, M.B.; FERREIRA, L.O. Alterações hematológicas e gravidez. Rev. Bras. Hematol. Hemoter., v.24, p.29-36, 2002. 